\title{
Lumen Gentium 1-8. Redescubrimiento del carácter cristológico de la Iglesia
}

\author{
Lumen Gentium 1-8. Rediscovery of the \\ Christological Character of the Church
}

\author{
Francisco José Fernández García \\ Facultad de Teología San Isidoro de Sevilla \\ franjotafernandezgarcia@gmail.com \\ IR ORCID 0000-0003-2497-3686
}

Resumen: En las siguientes líneas se pretende un acercamiento al «concepto» de Iglesia que surge del Concilio Vaticano II, especialmente de los ocho primeros números de la Constitución Dogmática Lumen Gentium, donde se define a la Iglesia como misterio. Para ello, en un primer momento, y por medio de una inmersión en los textos teológicos y magisteriales del inminente pre-concilio, comprobaremos cómo la doctrina emanada del Vaticano II engarza perfectamente con la tradición precedente. En un segundo lugar, tomando como base principal los citados números de la Constitución Dogmática sobre la Iglesia, nos adentraremos en el análisis del significado de la noción misterio en cuanto a su aplicación a la Iglesia, principalmente desde la óptica de su relación con Cristo.

Palabras clave: Iglesia, Cristo, Encarnación, misterio, concilio, cuerpo, sociedad.

\begin{abstract}
The purpose of the following lines is an approach to the concept of Church risen from the Second Vatican Council, especially from the first eight numbers in the Dogmatic Constitution Lumen Gentium, where the Church is defined as mystery. In order to do that, in a first moment and by means of an immersion into the theological and magisterial texts of the imminent pre-council, we will prove how the doctrine originated from theVatican II connects perfectly with the preceding tradition. In a second moment and considering the numbers already mentioned as the main basis of the Dogmatic Constitution about the Church, we will go deeper in the analysis of the meaning of the concept mystery according to its application to the Church, mainly under the perspective of its relation with Christ.
\end{abstract}

Keywords: Church, Christ, Incarnation, mystery, council, body, society.

Los cincuenta y cinco años que han transcurrido desde la clausura del Concilio Ecuménico Vaticano II han supuesto un periodo de auténtica efervescencia en la producción teológica, especialmente en lo que muchos han considerado la gran novedad del Concilio: la 
reflexión acerca de la naturaleza y función de la Iglesia. La aportación doctrinal del Vaticano II supuso un revulsivo para la comprensión de la Iglesia, hasta ese momento escorada hacia una concepción socio-jurídica fruto del devenir histórico, especialmente el subjetivismo e individualismo que tienen su origen en el Renacimiento y la decadencia del papado, que proporcionaron a los reformadores protestantes un suelo fértil para ofrecer una alternativa eclesiológica «desjerarquizada» ${ }^{1}$ y que la contrarreforma derivada de los cánones de Trento y del proceso de estudio positivista y racionalista al que es sometido el concepto Iglesia en la Ilustración terminó acentuando².

El nuevo texto dogmático puso sobre el candelero teológico palabras clave como "pueblo de Dios», "colegialidad de los obispos», «ecumenismo»... En la Conferencia del Cardenal Joseph Ratzinger sobre la eclesiología de «Lumen Gentium» pronunciada en el congreso internacional sobre la aplicación del Concilio Vaticano II, organizado por el comité para el Gran Jubileo del año 2000, el entonces Precepto para la Congregación de la Doctrina de la Fe denunciaba las consecuencias del mal uso de estos términos, que habían sido tomados para la investigación teológica desde un punto de vista más socio-político que teológico. El uso marxista del concepto pueblo había generado una contraposición artificial entre la Jerarquía -considerada como clase dominante y opresora- y los fieles laicos, y la consecuente necesidad de consolidar la soberanía de la Iglesia en el pueblo ${ }^{3}$. Esta tergiversada comprensión de la Iglesia como Pueblo de Dios se acompañaba de una, también, malograda «eclesiología de comunión», que lejos de fundamentarse en el aspecto íntimo y vertical de la comunión entre Dios y el hombre, devino en una progresiva horizontalización del concepto. Este creciente inmanentismo en los postulados teológicos de algunos autores postconciliares suscitó y alimentó un artificioso debate respecto la prevalencia y autonomía de la Iglesia particular sobre la Iglesia universal, centrándose en el problema de la división de competencias entre la una y la otra ${ }^{4}$.

Cf. E. Bueno de La Fuente, Eclesiología, BAC, Madrid 1998, 9-10.

Cf. Ibíd., 11.

Cf. J. Ratzinger, «La eclesiología la Constitución Lumen Gentium», in Obras

Completas. VIII/1. La Iglesia signo los pueblos, BAC, Madrid 2015, 542.

4 Cf. Ibíd., 550-551. 


\section{LA ECLESIOLOGÍA DEL INMINENTE PRE-CONCILIO}

No se trata aquí de refutar uno a uno estos postulados eclesiológicos -tarea ya acometida por el propio Ratzinger en su conferencia-, tampoco de censurar la actividad teológica de sus autores, con lo que haríamos un flaco favor tanto a la Teología en cuanto ciencia, como a la Iglesia, a la que estamos llamados a comprender y amar cada vez con más perfección, sino de continuar la profundización en el texto conciliar con el objeto de esclarecer el misterio de la Iglesia. Para ello centraremos nuestra tarea en un aspecto fundamental: el carácter cristológico de la Iglesia y su total referencia y dependencia de la persona de Cristo. En este sentido hay que tener en cuenta que muchos de los grandes avances doctrinales del Vaticano II tuvieron una larga gestación en el seno de la Iglesia, de modo muy especial en el inminente preámbulo de su celebración. Sin ir más lejos, la imagen de la Iglesia como Pueblo de Dios, que hunde sus raíces en la Sagrada Escritura, es profusamente analizada por Michael Schmaus, quien se adentra en el estudio dogmático de la Iglesia a partir del origen etimológico del término alemán Kirche (casa de Dios), el griego Ekklesia (asamblea de los ciudadanos) y el hebreo Qahal (multitud de hombres reunidos) $)^{5}$, para a partir del testimonio del Nuevo Testamento asegurar la absoluta prevalencia de Dios en ella ${ }^{6}$. El autor germano, si bien no llega a afirmar de modo explícito el carácter mistérico de la Iglesia, sí asevera que no es posible definirla desde un punto de vista científico a causa de su «sobreabundancia», su «excesiva riqueza» y la «fuerza de su contenido». En este sentido -Schmaus- considera que la Iglesia y Cristo son lo mismo ${ }^{7}$.

No puede, por tanto, afirmarse que antes del Vaticano II solo se tuviese en cuenta la noción de san Belarmino, que veía a la Iglesia como una reunión de hombres vinculados por la confesión de la misma fe cristiana y por la participación en los mismos sacramentos bajo la dirección de los pastores jurídicos y sobre todo bajo la dirección de un representante de Cristo en la tierra, el Papa romano. Una definición en la que ciertamente no se hace referencia ni a la procedencia, ni a la fundación, ni a la misión de la Iglesia y que puede dar lugar a

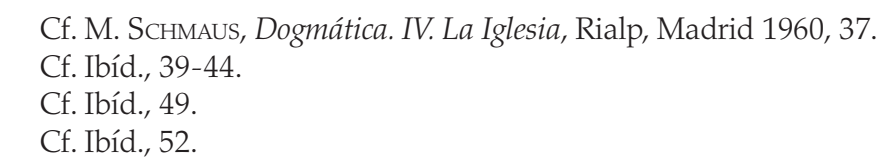


equívocos de tipo corporativistas. Johann Adam Möhler, apenas un siglo después concebía a la Iglesia como una comunidad visible -al igual que el santo Cardenal- pero fundada y dirigida por el propio Cristo, en la que se desarrollan las actividades que su fundador llevó a cabo durante su vida terrena para la purificación y santificación del género humano ${ }^{9}$. De este modo, Möhler, aporta una novedad importante en su definición: la Iglesia no puede ser considerada una corporación en la que son sus miembros los que determinan su estatus jurídico y sus fines, sino una institución donde el estatus es establecido por un fundador, que es además quien determina sus fines, no los miembros que la componen ${ }^{10}$. Pero además, el teólogo alemán comprende a partir de su dimensión visible que la Iglesia se asemeja al Hijo de Dios, llegando a afirmar que Ésta, la Iglesia, «es el Hijo de Dios que se encarna continuamente en figura humana» ${ }^{11}$, y que por ello la Sagrada Escritura la llama cuerpo de Cristo.

Una reflexión teológica que fue calando poco a poco en los pronunciamientos del Magisterio de la Iglesia. Así, el Vaticano I, en el prólogo de la Constitución Dogmática Pastor Aeternus, hace referencia a la edificación de la Iglesia por parte de Cristo con el objeto de la unión de todos los fieles en la misma fe y caridad ${ }^{12}$. El papa León XIII, en junio de mil novecientos ochenta y seis, con la intención de trazar una imagen de la Iglesia dibujando sus contornos ${ }^{13}$ publicó la carta encíclica Satis Cognitum. En ella, siguiendo la estela de la Tradición, afirma que la Iglesia es,

por su origen [...] una sociedad divina; por su fin y por sus medios inmediatos que la conducen es sobrenatural; por los miembros de que se compone, y que son hombres, es una sociedad humana. Por esto la vemos designada en la Sagrada Escritura con los nombres que convienen a una sociedad perfecta ${ }^{14}$.

De este modo, León XIII, además de por su finalidad: perpetuar la misión divina del Hijo hecho hombre; y de su misión: repartir entre los hombres y extender a todas las edades la salvación operada

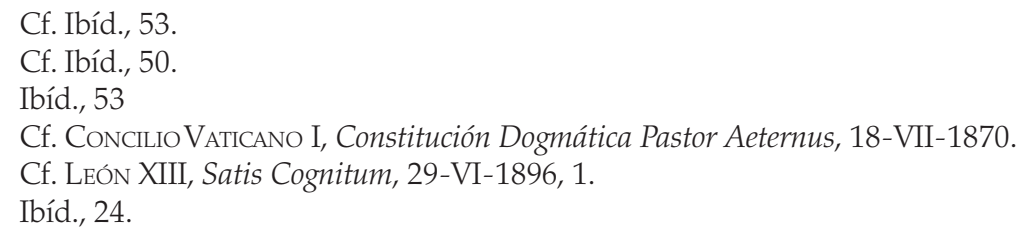


por Jesucristo y todos los beneficios que de ella se desprenden ${ }^{15}$; enfoca un aspecto determinante: la doble naturaleza humana y divina de la Iglesia, en razón de la cual, el ingente número de miembros de la Iglesia, lejos de ser una amalgama informe, está interrelacionado $\mathrm{y}$ «unido entre sí bajo el imperio de la Cabeza que todo lo dirige» ${ }^{16}$.

Pocos años más tarde, Pio XII en la Mystici Corporis Chisti, afirmará que si la Iglesia puede ser vista como un cuerpo, como el Cuerpo de Cristo, es precisamente por «estar formada por una recta y bien proporcionada armonía y trabazón de sus partes, provista de diversos miembros que convenientemente se corresponden los unos a los otros» ${ }^{17}$. Este acercamiento a la noción de cuerpo desde el concepto de sociedad perfecta, con el que se había definido a la Iglesia durante siglos, supone para nosotros, los cristianos nacidos y formados después de la celebración del Vaticano II, no el descubrimiento histórico del germen del cambio de la Iglesia, sino una auténtica revelación para el conocimiento de su significado. Del mismo modo que la cohesión de un cuerpo animado excede la mera unión física, «la unión del Cuerpo de Cristo es mayor que la pura unión moral. La unión moral está determinada sobre el fin al que todos tienden y por el que aúnan sus esfuerzos, mientras el fundamento de la unidad del cuerpo místico es de origen sobre natural: el Espíritu Santo.» ${ }^{18}$. El papa Pacelli, comprende la perfección de la Iglesia en cuanto sociedad, no desde el mero punto de vista moral, sino que reconoce su excelencia más allá de los elementos sociales y jurídicos que componen cualquier sociedad: en la gracia que sobrepuja a toda naturaleza, y por tanto toda estructura humana. Esta prevalencia de la gracia divina presume que, aunque la Institución haya sido fundada por el mismo Cristo en persona, lo que la eleva verdaderamente a un grado que está por encima de todos los órdenes de la naturaleza, es el Espíritu de nuestro Redentor que habita en ella. En último lugar, Pio XII, afirma que así como la dignidad del alma es superior a la del cuerpo, la estructura social de la Iglesia, que «pregona la sabiduría de su divino arquitecto», es inferior a los dones espirituales que la engalanan y vivifican ${ }^{19}$.

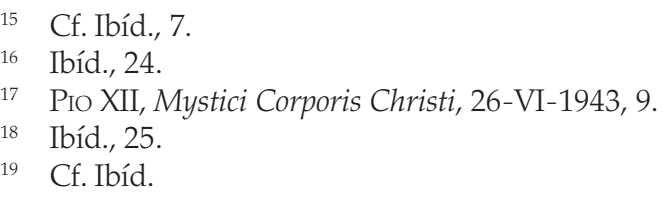


No hay por tanto un salto en la comprensión de la Iglesia que emana del Concilio Vaticano II. No hay discontinuidad ni ruptura con el Magisterio anterior. Es cierto que la doctrina conciliar supone una renovación profunda, pero no desde la negación o destrucción de la Tradición precedente; que supone también un cambio sorprendente, pero no profundo en cuanto a la noción esencial de la Iglesia ni surgido de la espontaneidad; que significa una renovación en sus instituciones, pero en ningún caso desde la sublevación o el levantamiento popular. El Concilio Vaticano II es fruto no de una «teología revolucionaria», sino de las mociones del Espíritu, que ilumina de modo admirable el conocimiento del misterio que la Teología está llamada a profundizar, y como ocurriera con los grandes concilios de la antigüedad cristiana no pueden ser interpretados a la ligera, sino que han de ser meditados, digeridos y asumidos desde el Espíritu ${ }^{20}$.

\section{CARÁCTER CRISTOLÓGICO DE LA IGLESIA A PARTIR DE LUMEN GENTIUM 1-8}

Entre las particularidades de la convocatoria del Vaticano II destaca el hecho de que san Juan XXIII no fijase ningún tema concreto para su celebración, sino que invitó a los obispos del mundo entero a proponer sus prioridades. Ante el abanico de posibilidades que se desplegaba ante los pastores de la Iglesia: continuar la reflexión eclesiológica del abruptamente interrumpido Vaticano I, dar respuesta a las cuestiones suscitadas en la recién terminada Guerra Mundial, el reto que planteaba la teología liberal... floreció entre los miembros de la Conferencia Episcopal Alemana -según recuerda Ratzinger en su conferencia sobre la eclesiología de Lumen Gentium - de la mano de Buchberger, benemérito obispo de Ratisbona, la certeza de que en el Concilio, ante todo y sobre todo, debía hablarse de $\operatorname{Dios}^{21}$. Dios es la única y verdadera respuesta a los anhelos de la humanidad. Dios es también la razón de ser, el fundamento del ser humano. Todas las crisis y la entera crisis que vive la humanidad responde al olvido de Dios, también la crisis de

\footnotetext{
20 Cf. AAS 54 (1962) 786; Discorsi-Messaggi-Colloqui del Santo Padre Giovanni XXIII, vol. IV, pp. 578-590

21 Cf. J. RATZINGER, «La eclesiología la Constitución Lumen Gentium», in Obras Completas. VIII/1. La Iglesia signo los pueblos, BAC, Madrid 2015, 539-540.
} 
la Iglesia en Europa y consecuentemente la crisis de identidad que sufren los países europeos. El Vaticano II trató sobre todo de Dios, y a partir de Él y subordinado a Él desarrolló su discurso sobre el mundo, la Iglesia y el Hombre ${ }^{22}$.

Para profundizar, pues, en el misterio de la Iglesia hay que penetrar en el de Cristo: su naturaleza divina, su relación con el Padre, su encarnación y misión para con la humanidad y la herencia y testamento que dejó a sus discípulos, no solo constituyen aspectos fundamentales del ser y la misión del Hijo eterno del Padre hecho hombre para la salvación y redención del mundo, sino que definen también la esencia y existencia de la Iglesia por él fundada. Unos principios cristológicos que afloran de modo luminoso en los primeros números de la Constitución Dogmática sobre la Iglesia y cuyo estudio proponemos aquí desde cuatro ejes fundamentales: la vinculación existente entre Iglesia y creación, la relación de la Iglesia con la encarnación del Verbo, el sacrificio de Cristo y su repercusión para la comunidad cristiana, y la Iglesia como sacramento. Y es que, desde sus inicios, Lumen Gentium deja claro que la razón de ser de la Iglesia responde al plan de Dios:

El Padre eterno, por disposición libérrima y misteriosa de su sabiduría y de su bondad, creó el universo, decidió elevar a los hombres hasta participar de su vida divina, y, caídos en Adán, no los abandonó, prestándoles siempre ayuda para la salvación, en consideración a Cristo Redentor, que es la imagen de Dios invisible, primogénito de toda la creación (Col 1, 15). Así, a todos los elegidos, el Padre, antes de los siglos, los distinguió de ante mano y los predestinó para que se configurasen a la imagen de su Hijo, a fin de que éste fuese el primogénito de una multitud de hermanos (Rom 8, 29). A los que creen en Cristo determinó convocarlos en la Iglesia santa, que, prefigurada dese el origen del mundo, maravillosamente preparada en la historia del pueblo de Israel y en la Antigua Alianza, fundada en los últimos tiempos, se manifestó por la efusión del Espíritu y se consumará gloriosamente al final de los siglos. Entonces, tal como se lee en los Santos Padres, todos los justos desde Adán, «desde Abel el justo hasta el último elegido» se congregarán junto al Padre en la Iglesia universal ${ }^{23}$.

Este texto expresa de modo sintético el designio ideado y establecido por Dios Todopoderoso desde la eternidad para llevar a cabo

\footnotetext{
22 Cf. Ibid., 541.

23 LG, 2.
} 
la salvación y redención del género humano. Un misterio, inaccesible a la sola razón humana, que se despliega a lo largo de la historia y al que el hombre tiene acceso fundamentalmente a partir de la revelación, pero también desde de la constatación del deseo interior -común a todos los hombres- de superar la propia inmanencia: de participar en la vida divina a la que hemos sido convocados por Aquel que nos creó de forma admirable - a imagen y semejanza suya -.

\subsection{Iglesia y creación}

Este designio misterioso de Dios para la humanidad puede ser resumido sintéticamente en la recapitulación en Cristo, es decir, en la configuración más perfecta de cada ser humano con el que es imagen de Dios invisible y primogénito de toda la creación ${ }^{24}$. De ahí que Dios vivo y verdadero, Señor del cielo y de la tierra, dispusiera en su infinita sabiduría al originar libremente todas las cosas, hacer un ser con una dignidad superior al resto con el que poder mantener una relación especial, «y creó Dios al hombre a su imagen, a imagen de Dios lo creó, varón y mujer los creó» ${ }^{25}$. Por este motivo, el ser humano, además de llevar en sí la huella dejada por el Creador como el resto de criaturas; al haber sido hecho según la Persona del Hijo Eterno, solo se aproxima a su realización plena en la manera en que más se asemeja y adhiere a su Modelo. Por esta razón, del mismo modo que el Dios Creador no es un ser misántropo y solitario, sino que es comunidad de Personas fundada en el amor, el ser humano no ha sido creado aislado y autosuficiente, sino que necesita y busca la cooperación de sus congéneres además de para la subsistencia personal, para alcanzar los bienes que desde la individualidad no puede conseguir.

La santa Iglesia -prefigurada desde la génesis del mundo, por la creación de una única humanidad compuesta de innumerables hombres y mujeres, preparada en la Historia de la Salvación y fundada en los últimos tiempos en la Persona de Jesús-; es el instrumento y signo querido por Dios para congregar a todos los hombres que creen en Cristo $^{26}$ y llevar así su plan a término.

\footnotetext{
Col 1, 15.

Gen 1, 27.

Cf. LG, 1 .
} 
La vida del hombre es con-vivencia y cristaliza en la formación de sociedades con un gran alto grado de cohesión, tanto es así, que en algunos casos, las masas llegan a pensar, sufrir y comportarse como un solo ser. De este modo, entre los cimientos sobre el que se construye la unidad que el hombre espera podemos reconocer la solidaridad. Hablar de solidaridad es hablar de la obligación contraída conjuntamente por un grupo, en la que cada miembro responde por el grupo y el grupo vela por el bien estar y los intereses particulares de cada uno de sus miembros, pero también es hablar de sufrimientos y alegrías, penurias y bonanzas compartidas. Junto a esta solicitud y dependencia del otro, la fe, como creencias compartidas, es otro de los pilares que sostienen la cohesión entre los hombres. Desde la fe -una y común a los miembros que la profesan- es desde donde brotan tanto las preguntas como las respuestas fundamentales para la identidad de un pueblo, así como la convicción religiosa para adoptar una determinada ética que garantice la dignidad, los derechos y las obligaciones de todos sus miembros. La Iglesia, por tanto, desde un punto de vista antropológico, no puede considerase un añadido externo o un intermediario burocrático para la dimensión religiosa del ser humano; pertenece a los más hondo de la esencia del hombre, creado y llamado a vivir en comunión. No obstante, no puede agotarse su definición en este carácter social, puesto que la Iglesia pertenece una esfera cualitativamente diversa.

\subsection{Encarnación e Iglesia}

La doctrina bíblica de la creación del ser humano a imagen y semejanza del Hijo Dios pone en la persona de Jesucristo el punto focal desde el que brota la Iglesia como Reino de $\operatorname{Dios}^{27}$ y Cuerpo Místico ${ }^{28}$, y por ende como sociedad, pues la cohesión a la que el hombre se siente llamado responde a la vocación que Dios ha inscrito en su corazón, y no puede verse cumplida mediante la mera unión social, sino que precisa sobre todo de la participación en la unidad divina del amor trinitario.

Es Jesucristo, Dios y hombre verdadero, segunda Persona de la Santísima Trinidad, quien asumiendo en la Encarnación la condición

\footnotetext{
27 Cf. LG 5.

28 Cf., LG 8.
} 
humana, lleva a plenitud el plan divino de la creación del hombre. De este modo el acontecimiento de la encarnación del Verbo afecta ontológicamente a cada ser humano, pues cuando lo imperfecto y finito de nuestra naturaleza fue asumido por lo perfecto e infinito de Dios, se vio liberada de todo cuanto la oprimía y arrastraba irremediablemente hacia la muerte. La encarnación de Cristo procura a todo hombre y mujer la posibilidad de disfrutar, ya en este mundo, la vida divina; de poseer en plenitud la existencia perfecta en el seno de la Trinidad. Un don grandioso que no se concede a los hombres de modo individual. Cristo asume nuestra naturaleza en su totalidad: asume todo lo humano y a todos los humanos, de modo que la realización perfecta de esta gracia está mediada por la unión de cada individuo con Cristo y por la de Cristo con todos. Esta común-unión se hace visible en la Iglesia, cuya realidad espiritual se revistió de carne en el mismo momento en que lo hizo el Hijo en el seno de María, la Virgen. En este sentido Lumen Gentium afirma:

Cuerpo místico de Cristo, grupo visible y comunidad espiritual, Iglesia terrestre e Iglesia dotada de bienes celestiales, no se deben considerar como dos realidades, sino que constituyen una sola realidad compleja, formada por un doble elemento: humano y divino. Por eso en virtud de una fundada analogía, se la compara con el misterio delVerbo encarnado ${ }^{29}$

La anunciación del Ángel trae al mundo la noticia de la encarnación delVerbo; la llegada a este mundo de la presencia viva, eficaz y tangible del único Dios, del Dios que salva y que prometió permanecer con-nosotros todos los días hasta el fin del mundo. La Iglesia, realidad de naturaleza espiritual, que se reviste de carne en la mañana de la Encarnación, sigue, a través de los siglos, asumiendo la naturaleza humana, con todas sus imperfecciones y debilidades, tal y como lo hizo Cristo, para llevarla al encuentro íntimo y redentor con la naturaleza de Dios.

Pues así -continua Lumen Gentium- como la naturaleza asumida está al servicio delVerbo divino, como un órgano vivo de salvación indisolublemente unido a Él, no de otro modo, el organismo social de la Iglesia está al servicio del Espíritu de Cristo, que le da la vida para que crezca el cuerpo ${ }^{30}$.

29 LG, 8.

30 Ibíd. 
La Iglesia, como Jesucristo, no es de este mundo, sino que tiene su origen en la Trinidad, y por eso, en ella prevalece por encima de todo: la inteligencia, la voluntad y la santidad de Dios. Pero del mismo modo que para la Encarnación fue indispensable el fiat de María al plan de Dios, para la Iglesia lo es la libre adhesión de sus miembros. Es la adhesión personal de los cristianos la que hace crecer la santidad ética que Dios espera de la Iglesia, y hace progresar la santidad óntica Dios otorga con su presencia.

\subsection{Sacrificio e Iglesia}

Además de la salvación obrada en la Encarnación, mediante la pasión, muerte y resurrección, Cristo redimió al género humano de la antigua culpa del pecado, y se constituyó primicia de los que reinarán a la diestra del Padre ${ }^{31}$. Solo Jesús, Dios verdadero, podía satisfacer la deuda de la que la humanidad entera era morosa en el acto de ofrecerse a sí mismo, hombre verdadero, como pago por los delitos de la multitud. Por su sacrificio la humanidad quedó reconciliada con Dios y el hombre fue sustraído de la esfera de lo profano y consagrado para la vida divina. Lumen Gentium afirma en este sentido:

El Hijo de Dios, en la naturaleza humana unida a sí, al triunfar de la muerte con su muerte y resurrección, redimió al hombre y lo transformó en una criatura nueva (Cf. Gal 6, 15; 2Cor 5, 17). Y cuando comunicó el Espíritu Santo a sus hermanos, llamados de entre toda la gente, hizo místicamente de ellos como su cuerpo ${ }^{32}$.

La expiración de Cristo en la cruz supone la redención del género humano y la inauguración de la Iglesia, nacida a este mundo con Cristo en la Nochebuena, y que brota ahora, junto con el agua y la sangre del costado abierto de Jesucristo dormido en la cruz.

Desde entonces, la Pascua de nuestro Señor se ha ido extendiendo a lo largo y ancho de este mundo, a través de los siglos, actualizando entre los hombres la obra magnífica de la redención. Si, como dice el Apóstol, la antigua condición humana ha sido crucificada con Cristo, quedando liberada del pecado y de la muerte ${ }^{33}$; la paz,

\footnotetext{
31 Cf. Ibíd., 2.

32 LG, 7.

33 Cf. Rom 6, 6-7.
} 
la justicia y la vida prometida por Dios a lo largo de la Historia de la Salvación nos han sido dadas en su Hijo.

\subsubsection{Comunión}

En efecto, la encarnación del Hijo de Dios supone la desaparición del abismo infranqueable que apartaba a los hombres de Dios. En su persona se da la comunión plena y perfecta entre lo humano y lo divino $^{34}$. La Iglesia, es «hueso de sus huesos y carne de su carne ${ }^{35}, \mathrm{y}$ a semejanza de su Esposo, siendo una y única alberga en sí la naturaleza divina y espiritual, y la naturaleza humana y material, sin que por ello se dé en Ella división ni separación alguna ${ }^{36}$, sino que se manifiesta como un solo cuerpo en Cristo ${ }^{37}$, y como tal, sus miembros se relacionan entre sí para su subsistencia y progreso bajo el gobierno de su Cabeza ${ }^{38}$. Pero la Iglesia es además como un sacramento de Cristo ${ }^{39}$; es signo visible del Redentor ${ }^{40}$, por eso, como enseña Lumen Gentium, de manera similar a como un organismo natural se ve dotado de recursos para la vida y la salud de cada uno de sus miembros y del cuerpo entero, Cristo otorga a su Iglesia los sacramentos, mediante los cuales hace nacer a la Vida e incorpora nuevos miembros, fortalece a los ya injertos para la defensa y el amparo de la Iglesia, proporciona la salud mediante la penitencia a aquellos que están en riesgo y debilitan todo el cuerpo, y nutre a la vez que robustece la unión de las junturas y del cuerpo con la cabeza ${ }^{41}$. Todo ello por medio de la comunión con el Señor resucitado, especialmente en el sacramento de la Eucaristía, donde la Iglesia, comunidad de los que creen en el Señor, se configura en su propio cuerpo.

Es por tanto la Iglesia un organismo vivo en el que está presente y operante el mismo Señor: presente a través de la vida comunitaria, que Él mismo practicó durante su existencia terrena con sus discípulos, presente en los actos sacramentales, con los que sigue
Cf. Ibíd., 7.
Cf. Gen 2, 23a.
Cf. LG, 8.
Cf. Rom 12, 5.
Cf. LG, 8.
Cf. Ibíd., 1.
Cf. Ibíd., 7.
Cf. Ibíd., 3. 
favoreciendo al hombre en cada época y lugar; presente en las enseñanzas del Magisterio, que emanan de sus palabras y gestos, y que son transmitidas en su Nombre por los discípulos que Él mismo designa; presente en el sufrimiento y en la entrega de los que se han unido a Él por medio del Bautismo y viven conforme a la vocación que ha sido inscrita en sus corazones. La Iglesia transluce a Cristo en su propia naturaleza mistérica, humana y divina, y prolonga eficazmente la acción salvífica del Hijo obrando la santificación y redención de sus miembros y anunciando el Reino de Dios para los que aún no han tenido la dicha de encontrarse con Jesús.

\subsubsection{Prolongación del misterio de Cristo}

Cristo es la luz del mundo, que ilumina a su Iglesia para que Ella pueda a su vez, alumbrar a todos aquellos que se hallan en la tiniebla de la ignorancia ${ }^{42}$ que les impide acceder a la plena comunión a la que el hombre ha sido predestinado por Dios. Este deseo, el del amor a Dios, exige para su realización el previo conocimiento de la persona amada. Por este motivo, la luz de Cristo ilumina también a la Iglesia para que los seres humanos descubran en ella la imagen del que buscan; pues para conocer verdaderamente a Cristo hay que conocer a la Iglesia; que desarrolla y actualiza a lo largo de los siglos las actitudes del Maestro.

Ella como Cristo se entrega a la oración constante, donde se refugia en tiempos de dificultad, persecución o pandemia, de donde capta la exigente belleza de su vocación y la confirmación de su misión. La oración revela así la existencia de la Iglesia en total referencia a quien llama Padre en los mismos términos que Cristo y reconoce en Dios su cielo y su suelo. En la oración, al igual que hiciera Cristo, la Iglesia no siente vergüenza de poner al descubierto sus debilidades y de ofrecer al Padre todas las energías que recibe de Él para entregarse obedientemente al seguimiento del mandato de amar a los hombres hasta el extremo.

La Iglesia también se muestra como Maestra y se entrega a la tarea docente como hizo Cristo su esposo: interpretando la Escritura con la gracia del Espíritu, proclamando la Doctrina con la autoridad

42 Cf. PAblo VI, La exaltada misión de la Iglesia «Lumen Gentium», Audiencia general del 22 de junio de 1966. 
con la que Él mismo la invistió, para que a través del Magisterio y de la vida familiar y social de los fieles difundiese la Verdad a todos los habitantes de la Tierra.

Del mismo modo se encuentra en la Iglesia la paciencia manifestada por Dios cuando se entregó a la minuciosa tarea de la creación y conservación del cosmos, o cuando tolera las afrentas de los hombres y sabe esperar la conversión de los que no deja de amar, pero sobre todo, cuando padece y soporta dolor, hambre, persecución o traición en sus miembros, actualizando así el valor redentor del sufrimiento de Cristo en la cruz, pues:

así como Cristo llevó a cabo la obra de la redención a través de la pobreza y de la persecución, también la Iglesia está llamada a caminar por el mismo camino, para comunicar los frutos de la salvación a los hombres ${ }^{43}$.

Es tal la identificación de la Iglesia con Cristo que, también es partícipe del encargo divino de anunciar e implantar el Reino de Dios en este mundo, pues ella, enseña Lumen Gentium,

provista de los dones de su Fundador y cumpliendo fielmente sus mandatos de caridad, humildad y abnegación, recibió la misión de anunciar el Reino de Cristo y de Dios y de establecerlo entre todos los pueblos, constituyendo el germen y el comienzo de ese Reino sobre la tierra. Entretanto, mientras va creciendo poco a poco, ansía llegar al acabamiento del Reino y con todas sus fuerzas espera y aspira a unirse con su Rey en la gloria ${ }^{44}$.

Una misión que lleva a cabo siendo germen entre los pueblos de modo análogo a cómo Cristo es primicia de la humanidad ${ }^{45}$ : ofreciendo a todo hombre, junto a la iluminación y el conocimiento de la Verdad, la posibilidad de la liberación de las fuerzas del mal, y por tanto la consecución de la libertad para amar a Dios y al prójimo ${ }^{46}$, y lo hace no de un modo humano -con la promulgación de leyes extrínsecas- sino buscando la conversión del corazón de cada uno de sus miembros.

Los evangelios, además de ofrecer el testimonio de la predicación del Reino de Dios por parte de Jesús, muestran otras imágenes de gran

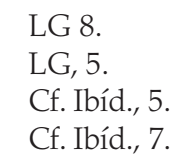


sentido teológico para anunciar la Buena Noticia. La Constitución dogmática Lumen Gentium toma, para ilustrar la naturaleza íntima de la Iglesia ${ }^{47}$ algunas de ellas

Bien de la vida pastoril o de la agricultura, bien de la construcción de edificios o incluso de la familia o de las bodas, y que ya están esbozadas en los libros de los Profetas ${ }^{48}$,

en las cuales se muestra a la Iglesia como un redil cuya única y necesaria puerta es Cristo, el Buen Pastor; como un campo de labran$z a$, donde crece la viña selecta plantada por Dios; como un edificio, cuya Piedra Angular, desechada por los poderes de este mundo, arma y sostiene todo el Templo, sitio de la presencia y lugar de encuentro entre Dios y los hombres, también llamada Jerusalén de arriba; la muestra también como la esposa inmaculada del Cordero, a quien Cristo amó y por quien se entregó para hacerla santa. Imágenes que guardan una profunda relación con la revelación que el Hijo de Dios hace de sí como Pastor, Viña, Templo y Espeso. Estas imágenes puestas en la boca de Cristo por parte de los evangelistas, o aplicadas a su Persona en distintos escritos, tienen la intención de mostrar, por un lado, la verdadera identidad de Quien pronuncia esas palabras y, por otro lado, hacer ver la verdadera naturaleza de la misión que le ha traído a este mundo.

\subsection{Iglesia sacramento}

La Iglesia, sociedad en perfecto orden, sigue las enseñanzas de su Maestro y prolonga a través de los siglos su presencia y obra en la tierra. Una historicidad, la de la Iglesia, que no debe ser entendida como la mera conservación de una tradición. En efecto, así como la encarnación, los misterios de la vida del Señor, su pasión, muerte y resurrección, están anclados en un momento determinado del tiempo y del espacio, pero afectan a toda la historia pasada, presente y futura del cosmos; la Iglesia es desde siempre y para siempre el modo en que Dios ha dispuesto salvar a la humanidad. La ascensión al cielo de Jesús no supone el desamparo y abandono de sus discípulos, de hecho, Jesús prometió estar con nosotros todos los días hasta el fin

47 Cf. Ibíd., 6.

48 Ibíd. 
de los tiempos ${ }^{49}$. La existencia de la Iglesia, en su curso histórico, responde a esta promesa del Señor y está profundamente marcada por la vida y las obras, la muerte y la resurrección de Jesucristo.

La Iglesia es como un sacramento -dice Lumen Gentium- y su forma sacramental -sacramento universal de salvación- se pone de manifiesto de muchas formas, especialmente en la celebración litúrgica de los sacramentos, que fueron instituidos por el propio Jesús ${ }^{50}$. Sacramentos que están fundados en los misterios de su vida terrena: en los actos cotidianos del hombre Jesús de Nazaret. Son, por tanto, actos salvíficos de Cristo, «el mismo ayer, y hoy, y siempre» ${ }^{51}$, eternamente operantes y actuales ${ }^{52}$. Los sacramentos, como fuerzas que brotan del cuerpo de Cristo y acciones del Espíritu del Señor, existen por y para la Iglesia ${ }^{53}$, como el mismo Señor dispuso cuando envió a sus discípulos para curar enfermos, resucitar muertos, limpiar leprosos y arrojar demonios con la fuerza que de Él mismo habían recibido, advirtiéndoles severamente no entrar en tierra de paganos ni en las aldeas de Samaría ${ }^{54}$.

\section{CONCLUSIÓN}

San Pablo dice que «hasta hoy toda la creación está gimiendo y sufre dolores de parto. Y no solo eso, sino que también nosotros, que poseemos las primicias del Espíritu, gemimos en nuestro interior, aguardando la adopción filial, la redención de nuestro cuerpo ${ }^{55}$, podemos comprender que la glorificación otorgada por el Padre al Hijo en la mañana de su resurrección no se limita al cuerpo físico que pendió de la cruz, sino a toda la humanidad por Él asumida en la Encarnación ${ }^{56}$.

El Concilio Vaticano II trabajó fatigosamente para dar una imagen simple y lineal de la Iglesia, y se encontró, no obstante, ante una realidad tan rica en su significado y existencia, tan grande y compleja

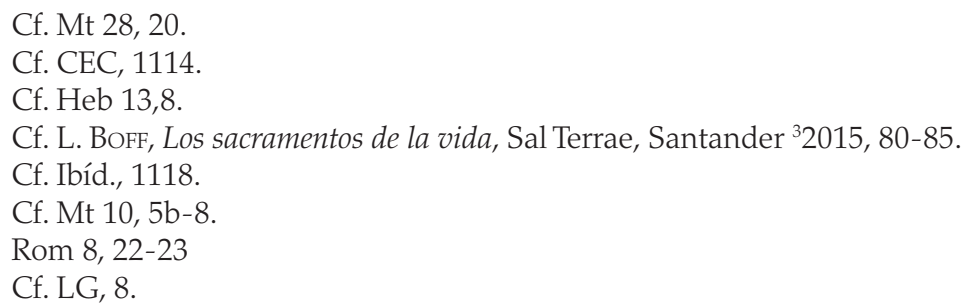


que ha tenido que llamarla «misterio» ${ }^{57}$. El misterio de la Iglesia es, en definitiva, el misterio de Cristo, su nacimiento, su bautismo, su amor a la humanidad, su solicitud por los hombres, pero también, su pasión, muerte y resurrección que están aún en desarrollo en la Iglesia hasta la plena manifestación de la Gloria del Hijo, cuando su Cuerpo esté completo.

En la alocución que san Pablo VI dirigió a los Padres Conciliares en el primer aniversario de la apertura del Vaticano II en la basílica de Santa María la Mayor, el Papa imploraba a la Virgen su bendición para la Iglesia, «también ella engendradora de cristianos hermanos de Cristo, primogénito de la humanidad redimida ${ }^{58}$ para que en el importante ejercicio de definirse a sí misma en el que se encontraba inmersa, la reconociera a Ella como «madre, hermana e hija predilecta ${ }^{59}$. Con esta referencia de la Iglesia a María en términos similares a los que podrían aplicársele en su relación con Cristo, no solo se actualizan las palabras pronunciadas por el Señor en aquella ocasión que la Santísima Virgen fue a buscarlo a la casa donde estaba reunido con sus discípulos: «Estos son mi madre y mis hermanos. El que cumple la voluntad de mi Padre del cielo, ése es mi hermano y mi hermana y mi madre. ${ }^{60}$, sino que estas palabras suponen una especie de identificación entre Cristo y la Iglesia, quien reconoce a María como Madre desde que la recibió en la persona del Discípulo Amado en la cima del Calvario ${ }^{61}$; como Hermana, en cuanto que Ella es perfectamente humana - el orgullo de nuestra raza, la bendita más que todas las mujeres de la tierra - que con no vaciló en exponer su vida a causa de la humillación de la humanidad ${ }^{62}$; y como Hija Predilecta, pues también ella fue discípula de Cristo y testigo de la resurrección.

La gran aportación eclesiológica del Vaticano II, es sin duda, la aplicación de la noción misterio a la Iglesia. Con ella se asume la reflexión teológica pre-conciliar y se manifiesta la imposibilidad de abarcar exhaustivamente la comprensión de la Iglesia desde la

57 Cf. PABlo VI, Ama a la Iglesia para alcanzar a Cristo y ascender a Dios, Audiencia general del 27 de abril de 1966.

58 Cf. PABLoVI, Alocución a los Padres Conciliares en el primer aniversario del comienzo del Concilio Vaticano II, 11-X-1963.

59 Cf. Ibid.

60 Mt 12, 50.

61 Cf. Jn 19, 26-27.

62 Cf. Jdt 13, 18-20. 
sola razón humana. Pero además, lejos de levantar las manos en la apremiante tarea del estudio y comprensión que la Iglesia requiere, al «definirla» como misterio, el Concilio la reconoce como parte del designio de salvación ideado y establecido por el Padre desde la eternidad para recapitular todas las cosas en Cristo. El misterio está siembre en relación con la Verdad una y suprema de Dios y su economía de la salvación. Es más, ninguna realidad o acontecimiento puede ser mistérico si su núcleo no tiene su origen y fundamento en Dios. Tanto es así, que no puede hablarse de «misterios del cosmos», de «misterio de humanidad», o de «misterio de la salvación» sino solo del misterio único de Jesucristo, verdadero Dios y verdadero hombre: raíz y motivo de la salvación humana ${ }^{63}$.

Un acercamiento a la Iglesia sin tener presente su dimensión mistérica sería similar a un acercamiento a Jesucristo sin tener en cuenta su procedencia y naturaleza divina. Es cierto que la persona de Jesús de Nazaret puede ser estudiada desde la historia, la biología, la política, la sociología... Puede ser, y de hecho lo es, estudiada aplicando únicamente los criterios de la ciencia moderna. No obstante, los resultados de este tipo de estudios son, en el mejor de los casos, solo parciales. Intentar analizar a la Iglesia únicamente a partir de sus manifestaciones históricas o de su estructura visible, obviando su procedencia y misión divina y su dimensión sobrenatural, ofrecería una imagen de la misma del todo errónea y alejada a su realidad. La Iglesia, al igual que Jesucristo, debe ser estudiada y comprendida desde la óptica de la fe, que proporciona un nivel de conocimiento, que si bien no puede definirse como diverso al de las ciencias modernas, lo supera y complementa.

El Concilio Vaticano II, además de recibir y acreditar los avances de la ciencia teológica de los siglos que le preceden, dejó para los teólogos de las generaciones posteriores a su celebración, un marco bien definido para un verdadero avance de la Eclesiología. Un avance cuya consecución pasa por el seguimiento de la senda de la hermenéutica de la continuidad, pues la Teología es eminentemente deductiva: se dedica al estudio de lo que ya le ha sido dado y progresa en él gracias a la asistencia de Quien le ha otorgado ese conocimiento. No caben en ella, por tanto, descubrimientos «revolucionarios» que

63 Cf. G. IAmmarrone, «Misterios de Cristo», 645, in Diccionario teológico Enciclopédico, Evd, Estella 1995, 644-646 
impliquen la categórica negación de lo que ha ido acumulando en su haber a lo largo de los siglos. Un avance que pasa también por «insertar y subordinar el discurso sobre la Iglesia al discurso sobre Dios $»^{64}$, por acercarnos a las realidades divinas desde un punto de vista teo-lógico.

La Iglesia al ser, «sacramento de Jesucristo», lejos de ser un obstáculo, sirve para la unión íntima de los hombres con Dios y de todo el género humano entre $\mathbf{s i}^{65}$, es más, no tiene otra razón de ser.Y aun cuando no está conclusa y no conoce la hora en que esto ocurrirá, sabe bien cuál es su destino, En María, mujer de la fe hecha madre en el Calvario de todos los discípulos de Jesús, se ve realizado el «proyecto escatológico» de Dios para su Iglesia, lo que el pueblo de la Nueva Alianza está llamado a ser en plenitud: santo, preservado de todo pecado y comunidad de los habitantes del cielo ${ }^{66}$.

La Iglesia es imagen de Cristo, Cuerpo místico, grupo visible y comunidad espiritual, prolongación de la Encarnación ${ }^{67}$ donde Dios sigue obrando las maravillas de su amor: la comunión perfecta entre lo humano y lo divino. No obstante, Ella no es Cristo, no puede irradiar luz propia como tampoco la humanidad creada a imagen y semejanza del hijo alberga en sí la perfección a la que hace referencia su existencia, sino que refleja la luz de su lámpara, que es el Cordero $^{68}$. En ella no vemos la llama que arde, sino la luz que ilumina a las gentes.

64 Cf. J. Ratzinger, «La eclesiología la Constitución Lumen Gentium», in Obras Completas. VIII/1. La Iglesia signo los pueblos, BAC, Madrid 2015, 541.

65 Cf. LG, 1.

66 Cf. G. L. Müller, Dogmática. Teoría y práctica de la teología, Herder, Barcelona ${ }^{2} 2009,587-588$.

67 Cf. LG, 8.

68 Cf. Ibíd., 21, 23b. 
